\title{
Mixed convection heat transfer from confined tandem circular cylinders in cross-flow at low Reynolds number
}

\author{
H. Laidoudi*, M. Bouzit** \\ *Laboratoire des Sciences et Ingénierie Maritime (LSIM), Mechanical engineering faculty, USTO-MB, BP 1505, El -Me- \\ naouer, Oran 31000, Algeria, E-mail: hichemsoft19@Gmail.com \\ **Laboratoire des Sciences et Ingénierie Maritime (LSIM), Mechanical engineering faculty, USTO-MB, BP 1505, El - \\ Menaouer, Oran 31000,Algeria,E-mail: Bouzit_mohamed@yahoo.fr
}

cross $^{\text {ref }}$ http://dx.doi.org/10.5755/j01.mech.23.4.15258

\section{Nomenclature}

$B$ - volume expansion coefficient, $1 / \mathrm{K} ; C_{D^{-}}$drag coefficient; $d$ - cylinder size, $\mathrm{m} ; F$ - drag force, $\mathrm{N} ; g$ - gravitational acceleration, $\mathrm{m} / \mathrm{s}^{2} ; G r$ - Grashof number; $H$ - Channel width, m; $h$ - Local convective heat transfer coefficient, $\mathrm{W} /\left(\mathrm{m}^{2} \mathrm{~K}\right)$; $k$ - fluid thermal conductivity, $\mathrm{W} /\left(\mathrm{m}^{2} \mathrm{~K}\right) ; L_{d}$ - downstream distance, $\mathrm{m} ; L_{u}$ - upstream distance, $\mathrm{m} ; n_{s^{-}}$direction normal to the cylinder surface; $N u$ - average total Nusselt number; p- pressure, $\mathrm{Pa} ; P$ - dimensionless pressure; $\mathrm{Pr}$ - Prandtl number; $R e$ - Reynolds number; $R i$ - Richardson number; $S$ - gap distance, $\mathrm{m} ; T$ - temperature, $\mathrm{K} ; U$ - dimensionless stream-wise velocity; $u$ - stream-wise velocity, $\mathrm{m} / \mathrm{s} ; \quad V$ dimensionless cross-stream velocity; $v$ - velocity crossstream velocity, $\mathrm{m} / \mathrm{s} ; X$ - dimensionless stream-wise coordinate; $Y$ - dimensionless cross-stream coordinate; $y$ - crossstream coordinate, $\mathrm{m}$.

greek letters-

$\eta$ - dynamic viscosity, Pa s; $\rho$ - fluid density $\mathrm{kg} / \mathrm{m}^{3} ; \beta-$ blockage ratio; $\theta$ - dimensionless temperature;

subscript-

in - inlet; out - outlet; $w$ - wall; $\max$ - maximum; ave - average; $\mathrm{c}-$ critical.

\section{Introduction}

The flow over Bluff bodies occurs in many engineering applications such as the cooling of electronic components, heat exchangers, and mechanical fields. One of the fundamental configurations that can be used as bluff body is circular obstacle [1-5]. By reviewing literature, it reveals that it has not been studied enough especially in mixed convection heat transfer. Amir Nejat et al. [1] numerically investigated the flow of power-law fluids around series of tandem arrangement of two cylinders, the lattice Boltzmann method has been used to solve the governing equations. This work is only limited for hydrodynamic effect, the obtained results showed that the total drag coefficient of each cylinder increases by increasing the distance between the cylinders. Chaitanya N.S.K. et al. [2] carried out a numerical investigation of forced convection of Newtonian and NonNewtonian fluids across a pair of identical circular cylinders in side-by-side arrangement, this investigation based by solving the continuity, momentum and energy equations along with the appropriate boundary conditions. The results showed that the total drag coefficient decreases and average Nusselt number increases with $R e$ number for all distances studied between the cylinders. Also, Amir Nejat et al. [3] studied numerically by solving the governing equations (continuity, momentum and energy) heat transfer and flow field of Newtonian and non Newtonian around two cylinders with different cross-sectional form (elliptical and circular), they have found that the tandem of elliptical cylinders with aspect ratio of 0.5 can be more efficient than circular cylinders. Iman Harimi, et al. [4] forced convection heat transfer from two and three isothermal circular cylinders in tandem arrangement is studying numerically, the governing equations are solved for laminar unsteady flow regime by using finite element method, the research studied the effect of distance between cylinders. It is found that the force coefficients and the wake structure behind the cylinders depend strongly on the value of the spacing ratio. $\mathrm{H}$. Sayehvand et al. [5] numerical investigation of forced convection heat transfer from two tandem circular cylinders embedded in a porous Medium, it is found that by increasing the distance between the tandem cylinders, the total heat increases.

The flow pattern even becomes more complicated around the cylinders when the boundary layer separations are further influenced by heat transfer. It should be mentioned that for the low to moderate $R e$ number, the thermal buoyancy effect can significantly muddle the flow field [6 10]. The principal parameter that controls a relative effect of buoyancy is the Richardson number $R i$, defined as $R i=G r / R e^{2}$, where, $G r$ is Grashof number, and $R e$ is Reynolds number. This number determines the relative importance of forced and natural convection. The free convection dominates over the forced convection when $R i>1$, and the forced convection dominates when $R i<1$. Both the free and forced convection dominate equally when $R i$ is nearly approached to 1 .

Manu K. et al. [6] the numerical investigation of effect of cross-buoyancy mixed convection of flow field and heat transfer characteristics a long semi-circular cylinder in a confined channel has been studied in laminar regime by solving the governing equations, the results have been presented and discussed for range of conditions: $R e=1$ to 40 , $R i=0$ to $4, \operatorname{Pr}=0.71$ to $50, \beta=16.6 \%$ to $50 \%$, they found that, the drag coefficient increases with $R i$ number and/or blockage ratio. Sandip Sarkar et al. [7] they analyzed the combined effect of $P r$ number and $R i$ values on the wake dynamics and heat transfer past a circular cylinder in crossflow using finite element method. The computation carried out for $R e=80$ to $180, P r=0.7$ to 100 , and $R i=0$ to 2 . The results showed that the average Nusselt number decrease by increasing $R i$ number. H. Laidoudi et al. [8] they examined the effect of thermal buoyancy around symmetrically and 
asymmetrically confined circular cylinder submerged in incompressible Poiseuille liquid, this work is achieved only at fixed blockage ratios, $\beta=20 \%$. The governing equations have been solved by the package ANSYS-CFX, the results are presented in terms of streamlines and isotherms contours. Also, the total drag coefficient and heat transfer rate are computed for $R i=0$ to 4 and $R e=10$ to 40 at $P r=1$. The obtained results showed that the total drag coefficient increases and Nusselt number decreases with increasing Richardson number. Moreover, the eccentricity factor has the tendency to increase the heat transfer rate. Chatterjee D. et al. [9] numerical simulation of two-dimensional mixed convection around a two equal tandem square cylinders is carried out to understand the effect of thermal buoyancy and $\operatorname{Pr}$ number over those obstacles, the distance between cylinder is fixed at the value $S=4 d$. For that purpose, the governing equations have been solved by using finite element method in these rang of conditions: $\operatorname{Re}=1$ to $30, P r=0.7$ to $100, R i=0$ to 1 , and $\beta=10 \%$. It is found that the flow is completely steady for chosen ranges of parameters. Generally, the drag coefficient and Nusselt number of first cylinder is always higher than the second one. Sarkar S. et al. [10] Numerical results of mixed convective heat transfer from two identical cylinders in a uniform upward flow has been demonstrated at $R e=100$. The effect of aiding and opposing buoyancy is brought about by varying Richardson numbers. The governing equations are also solved by finite element method. The Strouhal number, drag coefficient and Nusselt number studied for different distance between the tandems, under buoyancy effect, the cylinders are found to oscillate at the same frequency. Moreover, Maximum heat transfer is found at the front face of second cylinder.

From the above survey, it is observed that there are limited resources on the coupled fluid flow and heat transfer over tandem circular cylinders under superimposed thermal buoyancy. Additionally, there is no reported work on mixed convection heat transfer for wide range of Richardson number over tandem circular cylinders with different distance between them at low Reynolds number.

Such structure (tandem circular cylinders) has many practical applications, such as using tandem tube in novel heat exchangers, cooling of electronic components, solar extraction system, cooling towers, oil and gas pipelines, etc. the objective of this research is to study the effect of thermal buoyancy on the fluid flow, heat transfer and other parameters such as drag coefficient, Nusselt number, and streamlines in laminar regime. To achieve this purpose, comprehensive numerical study is performed to investigate the laminar mixed convection heat transfer around a tandem circular cylinders using Newtonian fluid.

\section{Governing equation}

The flow is assumed steady, two-dimensional, laminar and incompressible, for which the governing conservation dimensionless equations of mass, momentum, and energy with constant thermo-physical properties along with Boussinesq approximation and negligible dissipation effect can be written in the following forms:

- Continuity:

$$
\frac{\partial U}{\partial X}+\frac{\partial V}{\partial Y}=0
$$

- Momentum:

$$
\begin{aligned}
& U \frac{\partial U}{\partial X}+V \frac{\partial U}{\partial Y}=-\frac{\partial P}{\partial X}+\frac{1}{\operatorname{Re}}\left(\frac{\partial^{2} U}{\partial X^{2}}+\frac{\partial^{2} V}{\partial Y^{2}}\right) \\
& U \frac{\partial V}{\partial X}+V \frac{\partial V}{\partial Y}=-\frac{\partial P}{\partial Y}+\frac{1}{\operatorname{Re}}\left(\frac{\partial^{2} U}{\partial X^{2}}+\frac{\partial^{2} V}{\partial Y^{2}}\right)+\operatorname{Ri\theta } .
\end{aligned}
$$

- Thermal energy:

$$
U \frac{\partial \theta}{\partial X}+V \frac{\partial \theta}{\partial Y}=+\frac{1}{\operatorname{RePr}}\left(\frac{\partial^{2} \theta}{\partial X^{2}}+\frac{\partial^{2} \theta}{\partial Y^{2}}\right)
$$

In the above equations $U, V, P, \theta, R e, R i$ and $P r$ are dimensionless fluid velocities, temperature, pressure, Reynolds number, Richardson number, and Prandtl number $(\operatorname{Pr}=0.1)$, respectively. The dimensionless forms of the variables are:

$$
\begin{aligned}
& U=\frac{u}{U_{\text {max }}}, V=\frac{v}{U_{\text {max }}}, X=\frac{x}{d}, Y=\frac{y}{d}, \\
& P=\frac{p}{\rho V_{\text {max }}^{2}}, \theta=\frac{T-T_{\text {in }}}{T_{w}-T_{i n}}, \\
& R e=\frac{\rho d U_{\text {max }}}{m}, R i=\frac{G r}{R e^{2}},
\end{aligned}
$$

where $G r$ is the Grashof number which can be written as:

$$
G r=\frac{g B\left(T_{w}-T_{i n}\right) d^{3} \rho^{2}}{\eta^{2}},
$$

where $g, B$ : is the gravitational acceleration, the volumetric expansion coefficient respectively. The drag coefficient is computed from:

$$
C_{D}=\frac{2 F}{\rho U_{\max }^{2} d},
$$

where $F$ is the total drag force exerted on cylinder surface. The heat transfer between the cylinder and the surrounding fluid is calculated by the Nusselt number. The local Nusselt number based on the cylinder dimension is given by:

$$
N u=\frac{h d}{k}=-\frac{\partial \theta}{\partial n_{s}},
$$

where $h$ is the local heat transfer coefficient, $k$ is the thermal conductivity of the fluid and $n_{s}$ is the direction normal to the cylinder surface. Surface average heat transfer at each face of the cylinder is obtained by integrating the local Nusselt number along the cylinder face.

\section{Computational domain and boundary condition}

The schematic of the flow domain as well as the hydrodynamic boundary conditions are indicated in Fig. 1. The distance between the center of the first cylinder and the channel inlet, $L_{u}$ is 10 times of the diameter of cylinder, $d$. The gap between the two cylinders centers measured by 
$S=(1.25$ to 5$) d$ which is considered to be a variable parameter; the distance between the center of the second cylinder and the channel outlet, $L_{d}$ is 20 times of the cylinder diameter. The height of channel is defined by the blockage ratio $\beta=(d / H)=0.2$.

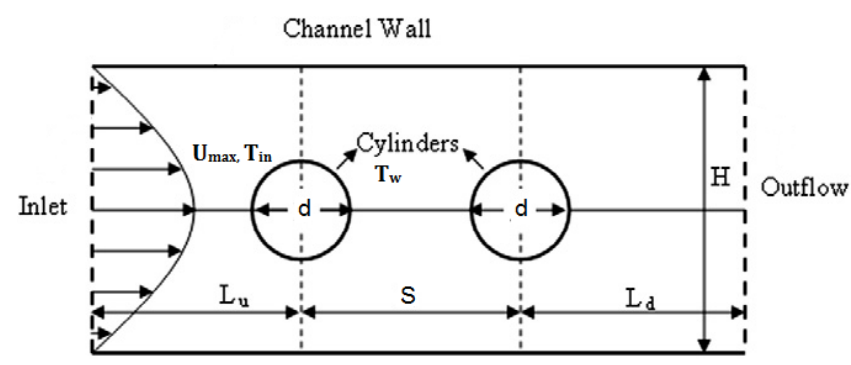

Fig. 1 Geometry of the problem

At the inlet a fully developed velocity profile for laminar flow fluids with a constant temperature, this is given by:

$$
u=U_{\max }(1-|2 y \beta|)^{2}, v=0, T=T_{\text {in }} .
$$

On the surface of the obstacle cylinder: The standard no-slip condition is used and the cylinder is maintained and heated with a constant temperature $T_{w}$.

$$
u=0, v=0, T=T_{w} .
$$

At the channel walls, the usual no-slip condition for flow and adiabatic condition for energy are used:

$$
u=0, v=0, \text { Adiabatic } .
$$

At the outlet Neumann boundary condition for field variables is employed:

$$
\frac{\partial U}{\partial X}=0, \frac{\partial V}{\partial Y}=0, \frac{\partial \theta}{\partial Y}=0
$$

\section{Grid independency study and validation}

In order to obtain reliable and accurate results, it is imperative to choose prudently the grid number. For that purpose grid independence test was carried out with respect to average values of Nusselt numbers for both tandem cylinders at Reynolds number of 10, and Richardson number of 0 , three different meshes were generated viz. Mesh1, Mesh2, and Mesh3. Tab. 1 shows the meshes and corresponding numbers of elements used in this study. Here $C_{N}$ is the numbers of nodes on the face of the cylinders. $S=5 \mathrm{~d}$. From Table 1 it is evident that the average Nusselt number of first cylinder shows variation of $0.0026 \%$, and $0.001 \%$ whether the second have $0.015 \%$ and $0.010 \%$ with meshes Mesh1 and Mesh3. So for the present computations the gridindependent situation was established for Mesh2 which is computationally economical for all different cases studied in this present work. All the computations are carried out in an Intel (R) Core (TM) 2 Duo CPU T5870@ 2.0 GHz PC computer.
Table 1

Control volumes effects on fluid flow and heat transfer parameters $\operatorname{Re}=10, \operatorname{Pr}=1, R i=0, S=5 d$.

\begin{tabular}{|l|l|l|l|l|}
\hline Grid & Elements & $C_{N}$ & $N u_{1}$ & $N u_{2}$ \\
\hline Mesh1 & 115064 & 200 & 2.26081 & 1.55778 \\
\hline Mesh2 & 210372 & 310 & 2.26087 & 1.55794 \\
\hline Mesh3 & 317764 & 400 & 2.26088 & 1.55824 \\
\hline
\end{tabular}

The numerical solution procedure used herein has been validated by comparing the present values with the previous results on mixed convection heat transfer from tandem square cylinders. The mixed convection for fluid flow over two equal isothermal square cylinders placed in a tandem arrangement within a horizontal channel in the range of this condition as, $1 \leq R e \leq 30$, for $\operatorname{Pr}=10$, and $R i=0.25$. The computed results are presented in Table 2. A good agreement is observed between predictive results and the results of [9], the maximum deviation is about $2.36 \%$.

Table 2

Comparison of $\mathrm{Nu}$ at different values of $\operatorname{Re}, \operatorname{Pr}$ for a square cylinder, $R i=0.25$

\begin{tabular}{|l|l|l|l|l|}
\hline \multirow{2}{*}{$R e$} & \multicolumn{2}{|l|}{ First cylinder } & \multicolumn{2}{l|}{ Second cylinder } \\
\cline { 2 - 5 } & $N u_{1}$ & $N u_{1}[9]$ & $N u_{2}$ & $N u_{2}[9]$ \\
\hline 1 & 1.79 & 1.8 & 1.8 & 1.3 \\
\hline 10 & 3.94 & 3.94 & 2.59 & 2.6 \\
\hline 30 & 6.37 & 6.4 & 3.78 & 3.83 \\
\hline
\end{tabular}

\section{Results and discussion}

\section{1. Flow field}

In this part the effect of the Reynolds number, distance between the cylinders and the buoyancy strength (Richardson number) over the flow field which presented by streamlines and the flow characteristics as drag coefficient were investigated. Fig. 2 shows the steady streamlines for three different distance $(S=1.25 d, 3 d$, and $5 d)$ at $R e=20$ for different $R i$ number namely $(R i=0,2$, and 4). Fig. 3 illustrates the streamlines for the same distances at $R i=2$ for different Reynolds number 10 and 40. Form Figs. 2 and 3 , it is observed that. For forced convection $(R i=0)$ as shown in the Fig. 2, as usual the flow is found to be symmetric about the centreline for all distances $S$. Closed steady recirculation forms behind the obstacles, the recirculation length for both tandems increase with increasing the distance between the cylinders, this trend is in line with that seen for [3]. However, the flow field loses its symmetry when the thermal buoyancy is superimposed. The degree of asymmetry is increased with increasing in the value of $R i$. It is also observed that the wake behind the cylinders vanished at all this due to the fact that as $R i$ increases for constant $R e$, the velocity of fluid particles behind the cylinder increases and moves toward the upper wall of channel. Consequently, the incoming flow will be accelerated underneath the confined obstacles owing to the mass conservation principle.

Furthermore, interesting observation is seen for this range of $R i>1$, a counter rotating region forms above the first cylinder. The region size increases along the stream-wise as well as transverse directions with $R e$ and/ or $R i$, this behavior can be explained as follow: above the value 
1 of $R i$, the free convection dominates over forced convection, and accordingly, most fluid flows below the cylinder. Hence, the mass flow rate becomes more beneath the cylinder than above it which reversals the flow above the first cylinder. Further, a second region appears over the first cylinder when the distance between obstacles is increased and/or the $R i$ increases.
Also a wake region is observed on the down wall of channel behind the second cylinder. This region is seen to be reduced in both directions by increasing the distance between the tandem obstacles. It is due to the thermal buoyancy effect, which tows the flow toward the upper wall behind the cylinders.

(a) $\mathrm{Ri}=0$
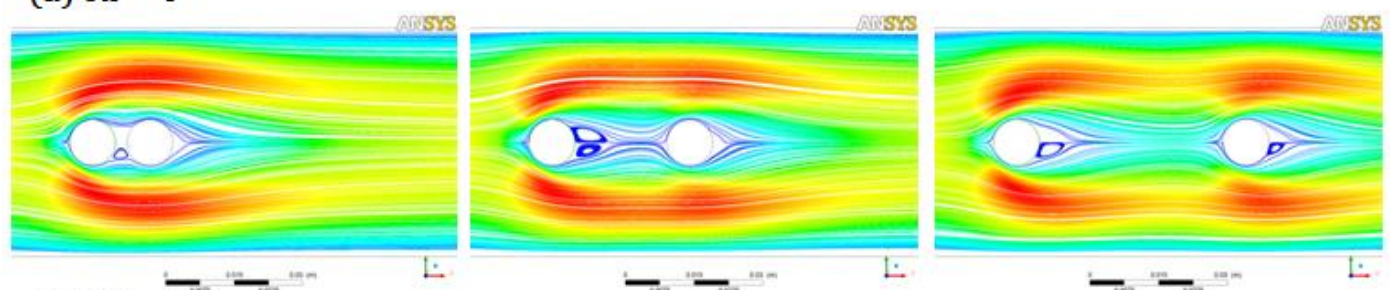

(b) $\mathrm{Ri}=\overline{2}$
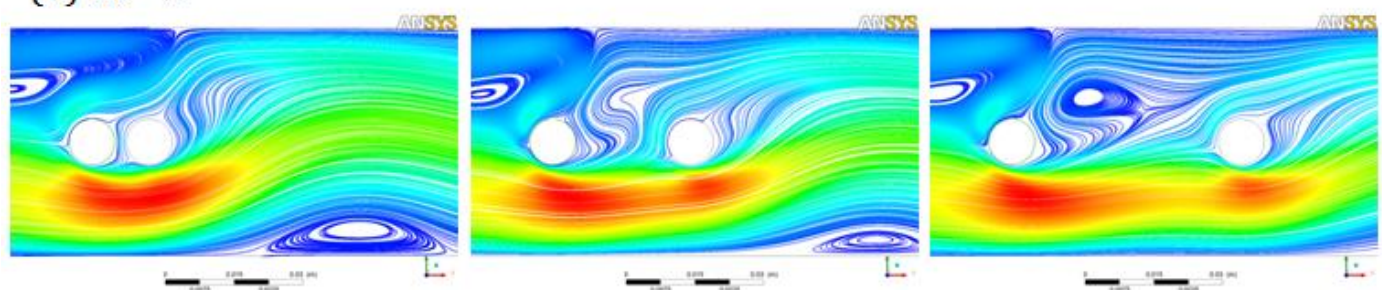

(c) $\mathrm{Ri}=4$
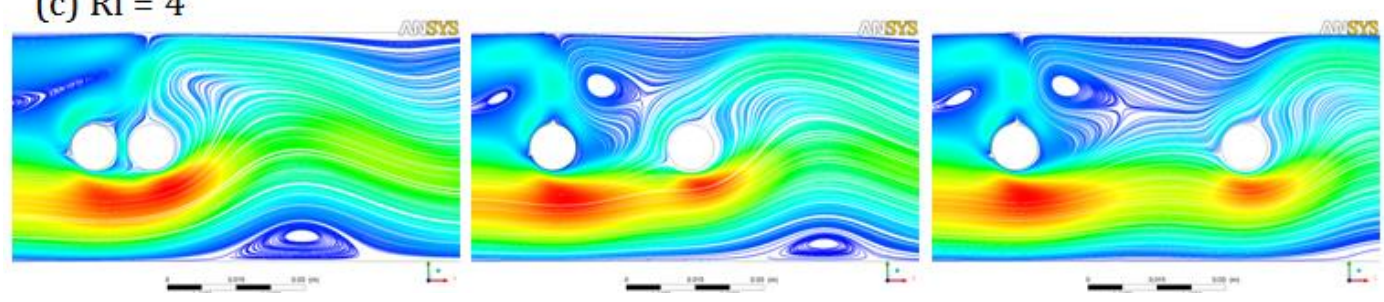

Fig. 2 Streamlines around the cylinders at $R e=20$, for at different $R i$ numbers and distance $S(1.25 d, 3 d$, and $5 d)$

(a) $\operatorname{Re}=10$

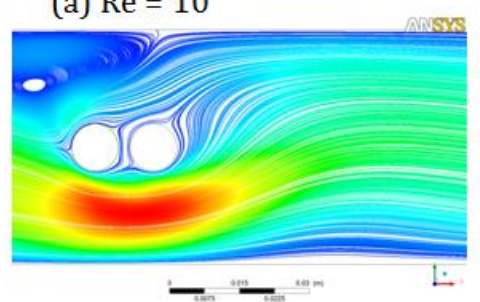

(b) $\mathrm{Re}=40$

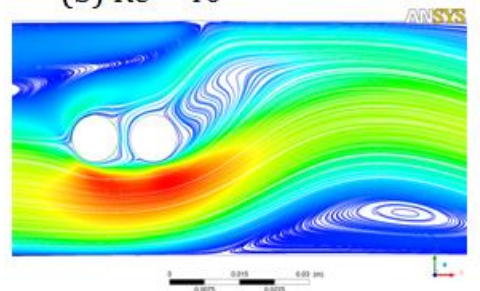

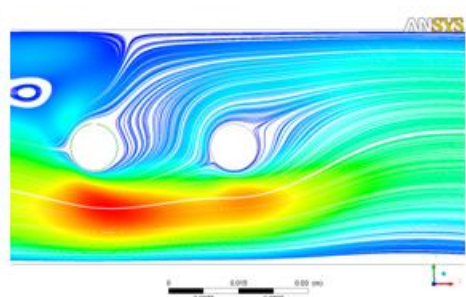

$-\ldots$

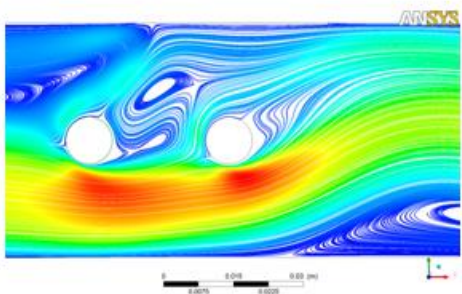

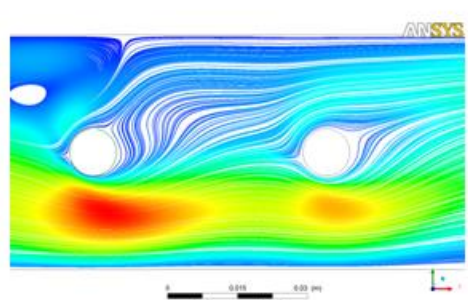

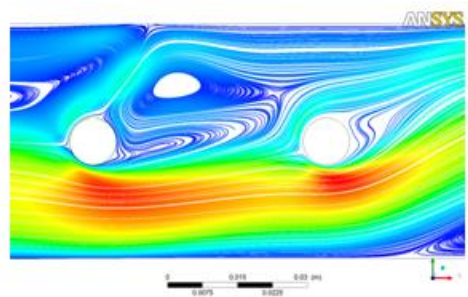

Fig. 3 Streamlines around the cylinders for $R e=1$ and 40 , at $R i=2$ for different distance $S(1.25 d, 3 d$, and $5 d)$

One of the main parameter which effected by the thermal buoyancy as well as wall the distance between cylinders is the drag coefficient. Wall proximity and buoyancy strength have different effect on the drag coefficient of the first and second cylinders. Fig. 4 shows the variation of the drag coefficient with Reynolds number for two values of $R i$ and different distances $S$. from those graphs, in a whole the values of $C_{D}$ show the expected inverse dependence on $R e$ for all distances. They also increase with an increase in the value of $R i$ number as shown in graph (a). Form graph (a) the value of the first cylinder is greater than the second for both values of $R i$, but a different behavior is seen for the second cylinder when the gap between the obstacles is increased as shown in the graph (b), and (c), this due to circulation zones that are formed between to obstacles and make a negative drag coefficient for $S=3 d$, and $5 d$. 

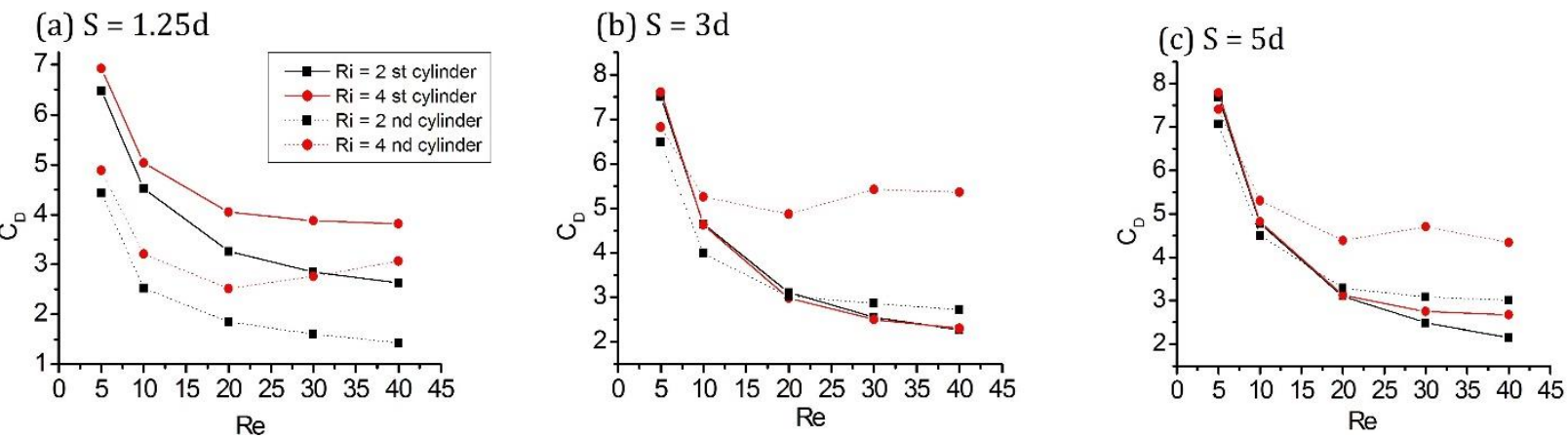

Fig. 4 Variation of drag coefficient with Reynolds number for $R i=2$, and 4 , at different $S(1.25 d, 3 d, 5 d)$

\section{2. Heat transfer}

In this part the effect of gap distance $(S)$, Richardson number $(R i)$, and Reynolds number $(R e)$ on the mixed convection heat transfer over the cylinders is explained. Isotherm contours are shown in the Fig. 5. The isotherm profiles are the reflection of physical phenomena observed from the analyses of streamlines patterns. More crowding of temperature contours are observed near to the curved surface of tandem cylinders compared to the flat surface

(a) $\mathrm{Ri}=0$
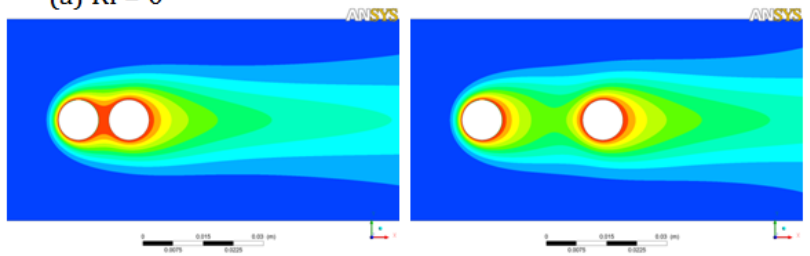

(b) $\mathrm{Ri}=2$
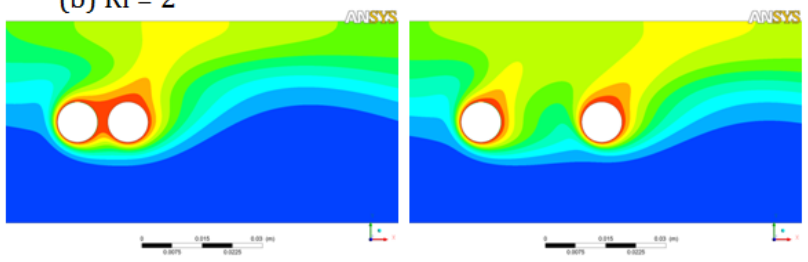

That results in a higher value of Nusselt number on the curved surface. The crowding of temperature contours is found to be increased with increase in $R i$ and/or $S$ this result indicates that the heat transfer is increasing with increasing $R i$ and/ or $S$. Also the isotherms are symmetric for $R i=0$, but the trend changes when the thermal buoyancy is superimposed. Furthermore, the thermal buoyancy influences the flow on the rear surface much more than that on the other surfaces of the cylinder.

Fig. 5 Isotherms around the tandem cylinders for $R i=0$, and 2 at $R e=20$ for the distance $S=1.25 d, 3 d$, and $5 d$

(a) $\mathrm{S}=1.25 \mathrm{~d}$

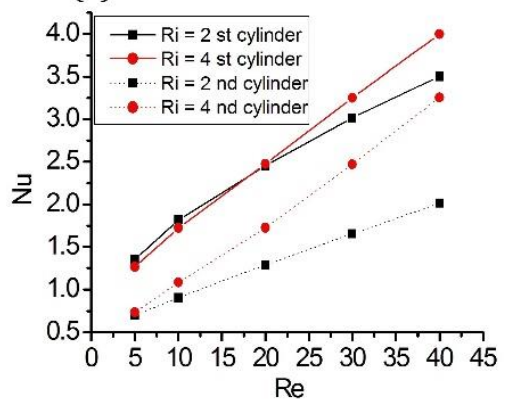

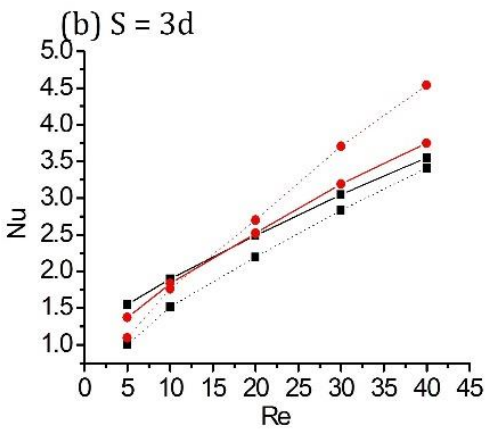

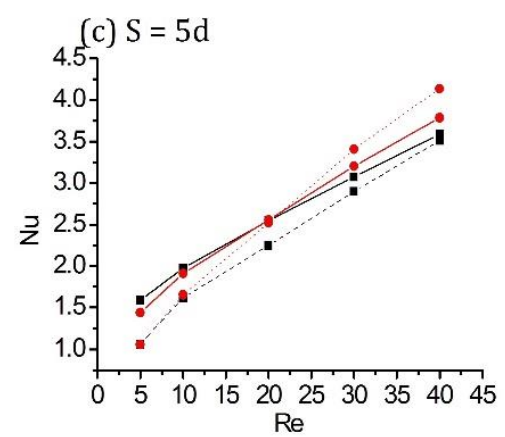

Fig. 6 Average Nusselt number of the tandem cylinders for different Reynolds numbers and $R i$ at $S=1.25 d, 3 d, 5 d$

Fig. 6 presents the variation of average Nusselt number with Reynolds number for different Richardson $R i=2$ and 4 number at different value of $S$ (gap between cylinder). As shown in Fig. 6, the average Nusselt number increases as usual with the Reynolds number for all distances due to the gradual thinning of the boundary layers with increasing $R e$. For $S=1.25 d$ graph (a), it is observed that increase $R i$ from 2 to 4 increases the heat transfer rate for both cylinders for all value of $R e$ number exception the first cylinder in the range 5 to 20 of $R e$, and this trend is seen for all gap distances $S=3 d$, and $5 d$ this due to the recirculation zone that is appeared over the first cylinder. However, form the graph (a) the value of Nusselt number of the first cylinder is greater than the second for both value of $R i$, but this behavior changes when the distance between the tandem obstacles increases, as shown in the graph (b), and (c). Moreover, an intersecting variation of $N u$ number is seen respect to gap distance, form all graphs (a), (b), and (c) it is depicted that in whole $\mathrm{Nu}$ increases slightly from $S=1.25 \mathrm{~d}$ 
to $3 d$ and then again decreases to $S=5 d$, surely that is due to appearance of wakes around the tandem cylinders.

\section{Conclusions}

The effect of mixed convection heat transfer of two isothermal tandem circular cylinders on the fluid flow and heat transfer for different gap spacing and buoyancy strength is investigated numerically in a horizontal plane channel. The main results are summarized as follow:

- A counter rotating region appears over the first cylinder and it increases by increasing $R i$ and/or $R e$.

- A second region appears also when the distance between the cylinders is increased.

- A wake zone forms behind the second cylinder and it is found to be decreased with increasing $S$.

- The total drag coefficient for the first cylinder is greater than the second for $S=1.25 d$, but this behavior changes for $S=3 d$ and $5 d$.

- The isotherm contours reflect the same physical behavior seen from the streamlines pattern.

- The average Nusselt number increases with $R e$ and/ or $R i$ for both cylinders for all gap distances exception for the first cylinder in the range of $R e=5-20$.

- The average Nusselt increases for $S=1.25 d$ to $3 d$ than again decreases for $S=5 d$.

- The thermal buoyancy suppresses the recirculation zones behind the tandem cylinders.

- The thermal buoyancy has tendency to increase the drag force coefficient and the average Nusselt number of the second cylinder more than the first.

- The gap space has difference effect under aiding thermal buoyancy on the first and second cylinder.

\section{References}

1. Amir, N.; Vahid, A.; Koohyar, V. 2011. Lattice Boltzmann simulation of non-Newtonian flows past confined cylinders. J. of Non-Newtonian Fluid Mechanics 166: 689-697. http://dx.doi.org/10.1016/j.jnnfm.2011.03.006.

2. Chaitanya, N.S.K; Dhiman, A.K. 2012. Non-Newtonian power-law flow and heat transfer across a pair of side-by-side circular cylinders. I. J. of Heat and Mass Transfer 55: 5941-5958.

http://dx.doi.org/10.1016/j.ijheatmasstransfer.2012.06.005.

3. Amir, N.; Vahid et al. 2012. Non-Newtonian powerlaw fluid flow and heat transfer computation across a pair of confined elliptical cylinders in the line array J. of Non-Newtonian Fluid Mechanics 171-172: 67-82. http://dx.doi.org/10.1016/j.jnnfm.2012.01.007.

4. Harimi, I.; Saghafian, M. 2012. Numerical simulation of fluid flow and forced convection heattransfer from tandem circular cylinders using over set grid method. J. of Fluids and Structures 28: 309-327. http://dx.doi.org/10.1016/j.jfluidstructs.2011.12.006.

5. Sayehvand, H.; Khalili Dehkordi ,E.; Basiri Parsa, A. 2015. Numerical Analysis of Forced Convection Heat Transfer from Two Tandem Circular Cylinders Embedded in a Porous Medium. Thermal Science.
http://dx.doi.org/10.2298/TSCI150307081S.

6. Manu, K; Sukesan; Amit, K. Dhiman. 2014. Laminar mixed convection in a channel with a built-in semicircular cylinder under the effect of cross-buoyancy. I. Communications in Heat and Mass Transfer 58: 25-32. http://dx.doi.org/10.1016/j.icheatmasstransfer.2014.08.025.

7. Sarkar, S.; Dalal, A.; Biswas, G. 2011. Unsteady wake dynamics and heat transfer in forced and mixed convection past a circular cylinder in cross flow for high Prandtl numbers. I. Journal of Heat and Mass Transfer 54: 35363551 . http://dx.doi.org/10.1016/j.ijheatmasstransfer.2011.03.032.

8. Laidoudi, H.; Bouzit, M. 2016. Mixed convection in Poiseuille fluid from asymmetrically confined heated circular cylinder. Thermal Science 00: 172-172. http://dx.doi.org/10.2298/TSCI160424172L.

9. Chatterjee, D.; Amiroudine, S. 2010. Two-dimensional mixed convection heat transfer from confined tandem square cylinders in cross-flow at low Reynolds numbers. I. Communications in Heat and Mass Transfer 37: 7-16.

http://dx.doi.org/10.1016/j.icheatmasstransfer.2009.10.007.

10. Sarkar, S.;Dalal, A.; Biswa,s G. 2010. Mixed convective heat transfer from two identical square cylinders in cross flow at $\mathrm{Re}=100$. I. J. of Heat and Mass Transfer 53: 2628-2642.

http://dx.doi.org/10.1016/j.ijheatmasstransfer.2010.02.053.

\section{H. Laidoudi, M. Bouzit}

\section{MIXED CONVECTION HEAT TRANSFER FROM CONFINED TANDEM CIRCULAR CYLINDERS IN CROSS-FLOW AT LOW REYNOLDS NUMBER}

\section{S u m m a r y}

Numerical simulations of mixed convective incompressible flow in a horizontal plane channel with adiabatic walls over two isothermal tandem circular cylinders of equal size are presented to investigate the effect of wall proximity of obstacles, gap space (i. e. gap between two cylinders), Reynolds number, and Richardson number. Computations have been carried out by using package ANSYS$C F X$ to solve the governing equations, for Reynolds numbers of 5 to 40, and Richardson number of 0 to 4 . Results show that, gap space has different effect under aiding thermal buoyancy on first and second cylinder in fluid characteristics as well as heat transfer effect.

Keywords: Steady flow, Thermal buoyancy, Flow suppression, Nusselt number Heat transfer, two tandem circular cylinder, total drag coefficient.

Received June 11, 2016 Accepted August 04, 2017 